\title{
A New PVC-Membrane Electrode Based on a Thia-Substituted Macrocyclic Diamide for Selective Potentiometric Determination of Silver Ion
}

\author{
Mojtaba Shamsipur, Sayed Yahỵa Kazemi, Khodabaksh Niknam, and Hashem Sharghi ${ }^{\dagger}$ \\ Deparment of Chemistry Razi Entwersity, Kermanshah, Iran \\ ${ }^{\dagger}$ Department of Chemistry, Shiraz Lniversity, Shiraz, Iran \\ Received June 26, 2001
}

\begin{abstract}
A new PVC-membrane electrode for $\mathrm{Ag}^{+}$ion based on a thia-substituted macrocyclic diamide has been prepared. The electrode exhibited a Nernstian response for $\mathrm{Ag}^{-}$over a wide concentration range $\left(1.7 \times 10^{-6}-1.0\right.$ $\times 10^{-1} \mathrm{M}$ ). It has a response time $<15 \mathrm{~s}$ and can be used for at least 3 months without divergence. The proposed membrane sensor revealed good selectivities for $\mathrm{Ag}^{+}$over a variety of metal ions and can be used in a $\mathrm{pH}$ range 3.0-7.5. It has been used successfully for direct determination of $\mathrm{Ag}^{+}$in different real samples and as an indicator electrode. in the titration of silver ion.
\end{abstract}

Keywords : $\mathrm{Ag}^{+}$-selective electrode. PVC-membrane. Macrocylic diamide, Potentionetry,

\section{Introduction}

The toxicity, bio-availability and accumulation to particulate matter and sediment of heavy metal ions are well known to be strongly dependent on their activity rather than their total concentration. ${ }^{1.2}$ Thus. the activity measurements of these cations in aqueous systems is of vital importance from an environmental point of view. Ionophore-based PVCmembrane electrodes are well-established analytical tools routinely used for the measurement of the activity of a wide variety of different ions selectively and directly in complex biological and envirommental samples. ${ }^{1-6}$ The key ingredient of such plasticized PVC membranes is the incorporated ionophore. which defines the selectivity of the electrodes via selective conplex formation with the cation of interest

Due to their specific selectivity and extraction efficiency. crown ethers have been widely used as suitable neutral ionophores for constructing membrane-selective electrodes for alkali and alkaline earth cations. ${ }^{1+7}$ The substitution of some oxygen atoms of crown ethers by nitrogen and/or sulfur atonss will make then ideal candidates for use as ion carriers in the preparation of transition and heavy metal ionselective electrodes. ${ }^{7-13}$ where facile complexation and decomplexation of the ionophore is of vital importance.

During the past decade, increasing interest has been directed toward the design and synthesis of new functionalized macrocyclic ligands for specific analytical applications. including the construction of ion-selective electrodes ${ }^{14-16}$ The in-built configuration rigidity induced by $\mathrm{N}$-substituted amides in the periphery of benzomacrocycles invokes a preorganization leading to ionophoric selectivity. ${ }^{17-21} \mathrm{~A}$ number of macrocyclic diamides, prepared from salicylaldehyde derivatives and some appropriate diamine compounds, have been shown to possess wide applications in selective metal ion extraction. $=5$ Moreover, the use of some benzo-substituted macrocycles as ion carrier in preparation of PVC. based $\mathrm{Li}^{+}$and $\mathrm{Pb}^{2-}$ ion-selective electrodes has already been reported in the literature. ${ }^{26.27}$
Recently, we have used some new macrocyclic diamide derivatives, synthesized in our laboratories. as suitable neutral ionophores in the construction of PVC-membrane electrodes for $\mathrm{Sr}^{2+} .8 \mathrm{Zn}^{2+} .{ }^{29} \mathrm{Cu}^{2-}{ }^{31)}$ and $\mathrm{Hg}^{2+}$ ions. ${ }^{31}$ In the present paper. we report the first synthesis of 3,5-diaza4.5:13.14-dibenzo-21-hydroxy-19-methoxy-9-thia-6.12-dioxabicyclo[15.3.1] heneicosa-1(21), 17.19-triene-2.16-dione (I) and its successful use as an excellent neutral ionophore for the preparation of a highly selective and stable plasticized PVC-membrane electrodes for the potentionetric determination of $\mathrm{Ag}^{+}$ion over a wide concentration range.

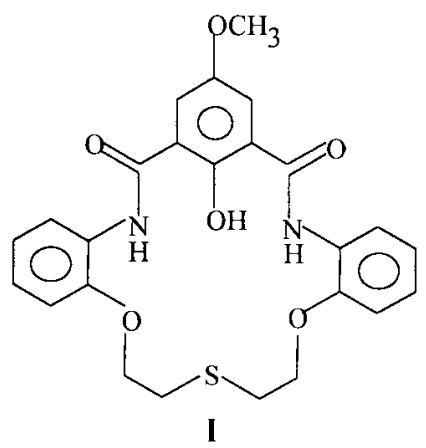

Experimental Section

Reagents. Reagent grade dibutyl sebacate (DBS). dioctyl phthalate (DOP), benzyl acetate (BA), o-nitrophenyl octyl ether (NPOE). potassium tetrakis(4-chlorophenyl) borate (KTCPB). tetrahydrofuran (THF) and high relative molecular weight PVC (all from Fluka) were used as received. The nitrate salts of all cations used (all from Merck) were of the highest purity available and used without further purification except for vacuum drying over $\mathrm{P}_{2} \mathrm{O}_{5}$. All other chemicals used were obtained from either Fluka or Merck and were used as received. Doubly distilled deionized water was used throughout.

Synthesis of Ionophore. 3.5-Diaza-4.5:13.14-dibenzo- 


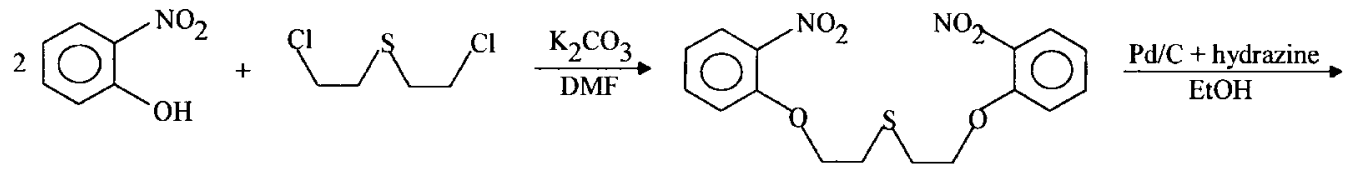

(1)

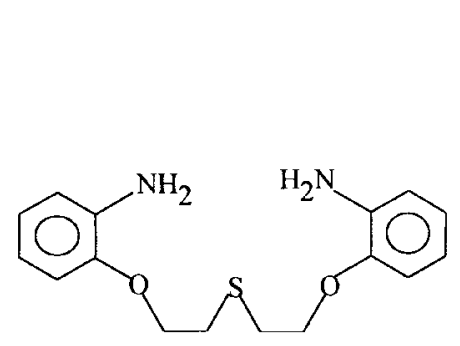

(2)

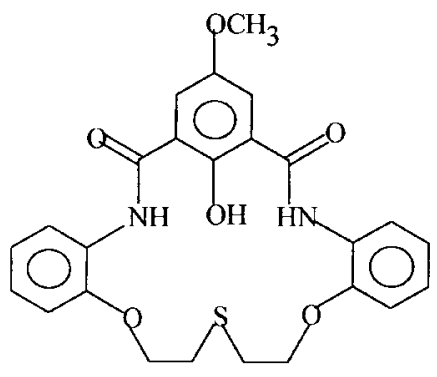

$(3, I)$ 21-hydroxy -19-methoxy -9-thia-6,12-dioxabicyclo[15.3.1]heneicosa-1(21),17,19-triene-2,16-dione $(\mathbf{I}, \mathbf{3})$ was synthesized in three steps as follows.

1.5-Bis(o-nitrophenoxy)-3-thiapentane (1): o-Nitropenol $(0.1 \mathrm{~mol})$ and potassium carbonate $(14 \mathrm{~g})$ were mixed and stirred in DMF ( $100 \mathrm{~mL})$ for $2 \mathrm{~h}$. Thiodiethylene glycol dichloride $(0.05 \mathrm{~mol})$ was added dropwise during $4 \mathrm{~h}$, and the mixture was refluxed for 3 days. After cooling. the mixture was poured into ice, and the resulting precipitate was filtered off. The precipitate was washed with distilled water. and the crude product was purified by columu chromatography, using petroleum ether $\left(\mathrm{bp}=60-80^{\circ} \mathrm{C}\right) / \mathrm{ethyl}$ acetate as eluent to give compound (1) as a pale yellow solid with $63 \%$ yield, $\mathrm{mp}=24.25^{\circ} \mathrm{C}$. The structure of compound (1) was confinmed by ${ }^{1} \mathrm{H}$ NMR and IR spectroscopy.

1,5-Bis(0-aminophenoxy)-3-thiapentane (2): In a twonecked round-bottomed flask $(250 \mathrm{~mL})$ equipped with a reflux condenser and a dropping funnel. a suspension of compound (1) $(0.012 \mathrm{~mol})$. palladium on carbon $5 \%(0.4 \mathrm{~g})$ and absolute ethanol was prepared. The nixture was warmed and, while being stirred magnetically, hydrazine hydrate $80 \%(10 \mathrm{~mL})$ was added dropwise over $1.5 \mathrm{~h}$ through the dropping funnel, while maintaining the temperature at about $50^{\circ} \mathrm{C}$. The reaction mixture was refluxed for $2 \mathrm{~h}$ and filtered while hot. On cooling, the filtrate gave the diamino compound (2). after vacuum drying, as white crystals (mp $=28$ $29^{\circ} \mathrm{C}$ ) with $89 \%$ yield. The structure of compound (2) was confirmed by ${ }^{~} \mathrm{H}$ NMR and IR spectroscopy.

3,5-Diaza-4,5;13,14-dibenzo-21-hydroxy-19-methoxy-9thia-6,12-dioxabicyclo [15.3.1]heneicosa-1(21),17,19-triene2,16-dione (I, 3): A solution of compound (2) (2 munol) in dry $\mathrm{CH}_{2} \mathrm{Cl}_{2}(50 \mathrm{~mL})$ was added quickly to a vigorously stiring solution of 4-methoxyphenol-2.6-dicarboxylic acid dichloride (2 numol) in dry $\mathrm{CH}_{2} \mathrm{Cl}_{2}(50 \mathrm{~mL})$ at room temperature. The reaction mixture was stirred for a further $20 \mathrm{~min}$ and washed with bicarbonate solution $(2 \times 50 \mathrm{~mL})$ and water $(2 \times 50 \mathrm{~mL})$. The organic layer was dried over magnesium sulfate. and the solvent was evaporated to give an oily product. The crude was purified by column cluromatography, using petroleum ether $\left(b p=60-80^{\circ} \mathrm{C}\right) /$ ethyl acetate as eluent. The pure product was obtained as a red solid; $\mathrm{mp}=154-156$ ${ }^{\circ} \mathrm{C}$. yield 66\%. IR (KBr, $\mathrm{cm}^{-1}$ ): 749.2 (s), $1051.5(\mathrm{~m}), 1253.0$ (s) 1454.5 (m). 1535.1 (m). $1602.2(\mathrm{~s}), 1662.7$ (s). 2918.7 (s) 3301.5 (s): ${ }^{1} \mathrm{H}$ NMR (CDCl${ }_{3}$. ppm): 3.31 (t. $4 \mathrm{H}, J=6.30$ Hz). $3.86(\mathrm{~s}, 3 \mathrm{H}) .4 .37(\mathrm{t}, 4 \mathrm{H} . J=6.30 \mathrm{~Hz}), 7.03-7.06(\mathrm{~m}$, $6 \mathrm{H}) .8 .08(\mathrm{~s}, 2 \mathrm{H}) .8 .65(\mathrm{~m} .4 \mathrm{H}), 11.70(\mathrm{~s}, \mathrm{lH}) ; \mathrm{MS}(\mathrm{m} / \mathrm{z} . \%)$ : $466\left(\mathrm{M}^{-}+\mathrm{I}-\mathrm{NH} .4 .1\right), 465\left(\mathrm{M}^{+}-\mathrm{NH}, 30.9\right) .464\left(\mathrm{M}^{-}+1-\right.$ $\mathrm{OH}$. base peak), 357 (11.3), 356 (91.8). 328 (4.1). 296 (26.8), $270(60.8), 268(32.0) .241(16.5), 226(39.2), 179$ (21.6), $178(17.5), 163(50.5) .152(27.8) .135(4.1), 120$ (32.0), 109 (17.5). 93 (11.3). 87 (88.7). 77 (15.5); UV, $\left(\mathrm{CHCl}_{3}\right.$. nu): 249.5, 378.0. 510.5; Elemental Analysis, Calculated for $\mathrm{C}_{23} \mathrm{H}_{24} \mathrm{~N}_{2} \mathrm{O}_{6} \mathrm{~S}: \mathrm{C}, 62.49: \mathrm{H} .5 .03 ; \mathrm{N}, 5.83: \mathrm{S}$, 6.67. Found: C. 62.17; H. 5.38: N, 5.52; S. 6.92 .

Electrode Preparation. The PVC-membranes were prepared by thorough mixing of $56.2 \mathrm{mg}$ plasticizer NPOE. 32 $\mathrm{mg}$ powdered PVC. $2 \mathrm{mg}$ ionophore I and $0.8 \mathrm{mg}$ additive KTCPB in $3 \mathrm{~mL}$ of THF. The resulting misture was transferred into a glass dish of $2 \mathrm{~cm}$ diameter. The solvent was evaporated slowly until an oily concentrated mixture was obtained. A Pyrex tube (3 mm o.d. on top) was dipped into the mixture for about $10 \mathrm{~s}$ so that a nontransparent menbrane of about $0.3 \mathrm{~mm}$ thichness was formed. The tube was then pulled out from the mixture and kept at room temperature for about $\mathrm{l} \mathrm{h}$. after which the tube was filled with internal filling solution $\left(1.0 \times 10^{-3} \mathrm{M}\right.$ silver nitrate). The electrode was finally conditioned for $20 \mathrm{~h}$ by soaking in a $1.0 \times 10^{-2} \mathrm{M} \mathrm{AgNO}_{3}$. A silver/silver chloride electrode was used as an intemal reference electrode.

Emf Measurements and Apparatus. All emf measurements were carried out by the following assembly:

$\mathrm{Ag} / \mathrm{AgCl} 3 \mathrm{M} . \mathrm{KCl} /$ internal solution, $1.0 \times 10^{-2} \mathrm{M} \mathrm{AgNO}_{3} /$ PVC membrane/test solution/ $\mathrm{Ag} / \mathrm{AgCl}$. $\mathrm{KCl}$ (satd.)

A Metrohm ion analyzer $\mathrm{pH} / \mathrm{mV}$ meter was used for potential measurements at $25.0 \pm 0.1^{\circ} \mathrm{C}$. Activities were calcu- 
lated according to the Debye-Huickel pocedure. ${ }^{33}$

NMR spectra were recorded using a Bruker Advance DPX-250 in pure deuterated solvents with tetramethylsilane as internal standard. IR spectra were obtained on an Impact 400 D Nickolet FTIR spectrometer. Mass spectra were determined on a Shinadzu GCMS-QP 1000 EX instrument at $70 \mathrm{eV}$. UV-Vis spectra were recorded on a PUB 700 spectrometer.

Determination of Silver from a Developed Radiological Film. A $69-\mathrm{cm}^{2}$ sheet of the film was left in a funnace for $2 \mathrm{~h}$ at $700{ }^{\circ} \mathrm{C}$. The residue was dissolved in hot $1: 1$ nitric acidwater and the $\mathrm{pH}$ of the resulting solution was adjusted to about 5 by a $\mathrm{NaOH}$ solution. Finally, the solution was completely transferred into a $250-\mathrm{mL}$ volumetric flask and diluted to the mark with water. The silver content of the solution as determined by AAS was found to be $5.0 \times 10^{-5}$ $\mathrm{M}$ (equivalent to $196 \mathrm{mg}$ silver per square meter of the film).

Determination of Silver from a Silver-Solder Sample. A $0.324 \mathrm{~g}$ of a sample of the silver solder was dissolved in 5 $\mathrm{mL}$ of concentrated nitric acid. and the solution was heated until fumes were observed. $5 \mathrm{~mL}$ of water was added to the solution after it had been cooled to room temperature, and the solution was again heated until funes were abserved. This treatment was repeated three times to ensure complete dissolution of the sample. The resulting solution was completely transferred into a $100-\mathrm{mL}$ volumetric flask and diluted to the mark with water. Finally, $2 \mathrm{~mL}$ of this solution was diluted to $500 \mathrm{~mL}$ in a volumetric flask with water. The concentration of $\mathrm{Ag}^{+}, \mathrm{Cu}^{2-}$ and $\mathrm{Zn}^{3+}$ ions in the diluted solution was deternined with AAS and found to be $6.2 \times$ $10^{-5} \mathrm{M} .5 .5 \times 10^{-5} \mathrm{M}$ and $3.0 \times 10^{-5} \mathrm{M}$. respectively.

\section{Results and Discussion}

Due to the vital importance of silver ion concentration measurements in industrial, pharmaceutical and environmental samples, ${ }^{3 \hat{j} .35}$ there have been recently an increasing number of reports on carrier-based $\mathrm{Ag}^{-}$-selective electrodes in the literature. ${ }^{7.36-4)}$ Ligands for use as ionophore in an $\mathrm{Ag}^{+}$ ion-selective electrode should fulfill the following conditions. They should be selective for $\mathrm{Ag}^{-}$over metal ions, they should have rapid exchange kinetics and should be sufficiently lipophilic to prevent leaching of the ligand into the solutions surrounding the membrane electrode. Our preliminary conductometric studies in DMSO solution revealed that carrier I possesses a tendency to form a relatively stable and highly selective complex with $\mathrm{Ag}^{+}$ion, compared with other transition and heavy metal ions. Thus, based on this information and the water insolubility of the ionophore. we decided to use the ligand $I$ as a potential ionophore in the preparation of a new PVC-membrane electrode for silver ion.

Optimum membrane ingredients were tested by changing the plasticizer/PVC ratio from 0.5 to 2.5 . while keeping the amount of ionophore constant (i.e. $2 \%$ ). The most sensitive. reproducible and stable results were obtained at a plasticizer/ PVC ratio of about 2. It is reported that the response

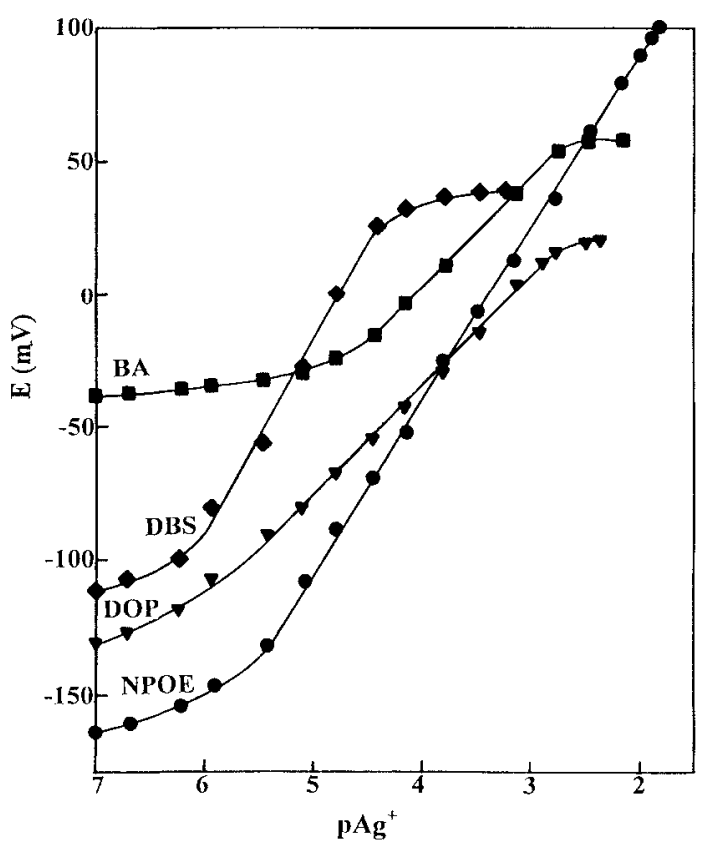

Figure 1. Effect of different plasticizers on the potential response of the $\mathrm{Ag}^{+}$ion-selective electrode.

characteristics of ion-selective electrodes are largely affected by the nature of the plasticizer used ${ }^{+1-44}$ This is due to the influence of the plasticizer on the dielectric constant of the membrane plase, the mobility of the ionophore molecules and the state of the ligands. ${ }^{15}$ Thus. in the present work we examined DBS. DDP. BA and NPOE as plasticizer and the resulting enf-pAg plots are shown in Figure 1 . As is quite obvious from Fig. 1. the use of NPOE results in a Nernstian linear plot over a wide concentration range, whereas in the case of other solvent mediators, the slope of the potentiometric response is much different from the expected Nernstian value of $59.5 \mathrm{mV}$ decade. although at a limited concentration range.

The optimization of the permselectivity of the PVCmembrane electrodes is known to be highly dependent on the incorporation of additional membrane components. ${ }^{44}$ In fact, it has been clearly demonstrated that the presence of the lipophilic negatively charged additives improves the potentiometric behavior of certain cation-selective electrodes not only by reducing the olunic resistance $e^{45.4 i}$ and improving the response behavior and selectivity. ${ }^{47.48}$ but also. in cases where the extraction capability of the ionophore is poor, by enhancing the sensitivity of the membrane sensor. ${ }^{19}$ Moreover, lipophilic additives may catalyze the exchange kinetics at the sample-membrane interface. ${ }^{5(!)}$ In the present work. we found that the use of $0.8 \% \mathrm{KTCPB}$ resulted in a Nenstian behavior and improved linearity. selectivity and stability of the electrodes response. Thus. membranes with an optimized PVC : NPOE : I : KTCPB percent ratio of 32:65.2:0.8 were prepared for further studies.

The influence of the concentration of the internal solution on the potential response of the $\mathrm{Ag}^{+}$-selective electrode was studied. The $\mathrm{Ag}^{-}$concentration was changed from $1.0 \times 10^{-2}$ 


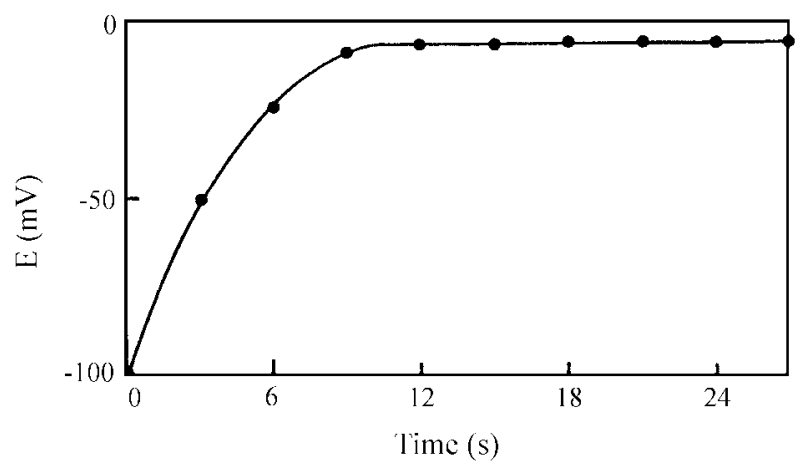

Figure 2. Response-time profile of the $\mathrm{Ag}^{-}$ion-selective electrode.

to $1.0 \times 10^{-4} \mathrm{M}$ and an enf $v s .-\log \left[\mathrm{Ag}^{+}\right]$plot was obtained. It was found that the variation in the concentration of the internal solution did not cause any significant difference in the potential response, except for an expected change in the intercept of the resulting plots. A $1.0 \times 10^{-\hat{3}} \mathrm{M}$ concentration of silver nitrate was quite appropriate for smooth functioning of the system.

The static response time of the electrode was found to be $<15$ s over the entire concentration range. A sample enf $v$. time plot is show in Figure 2. This is actually the average time required for the electrode to reach a potential within \pm 1 $\mathrm{mV}$ of the final equilibrium value after successive inmersion of a series of $\mathrm{Ag}^{+}$ions. each having a tenfold difference in concentration. The optinum conditioning time for the membrane electrode in a $1.0 \times 10^{-2} \mathrm{M} \mathrm{AgNO}_{3}$ solution was $20 \mathrm{~h}$. after which it generated stable potentials ion contact with $\mathrm{Ag}^{-}$ion solutions. The membrane electrode was used practically for 3 months, at a stretch. without any significant

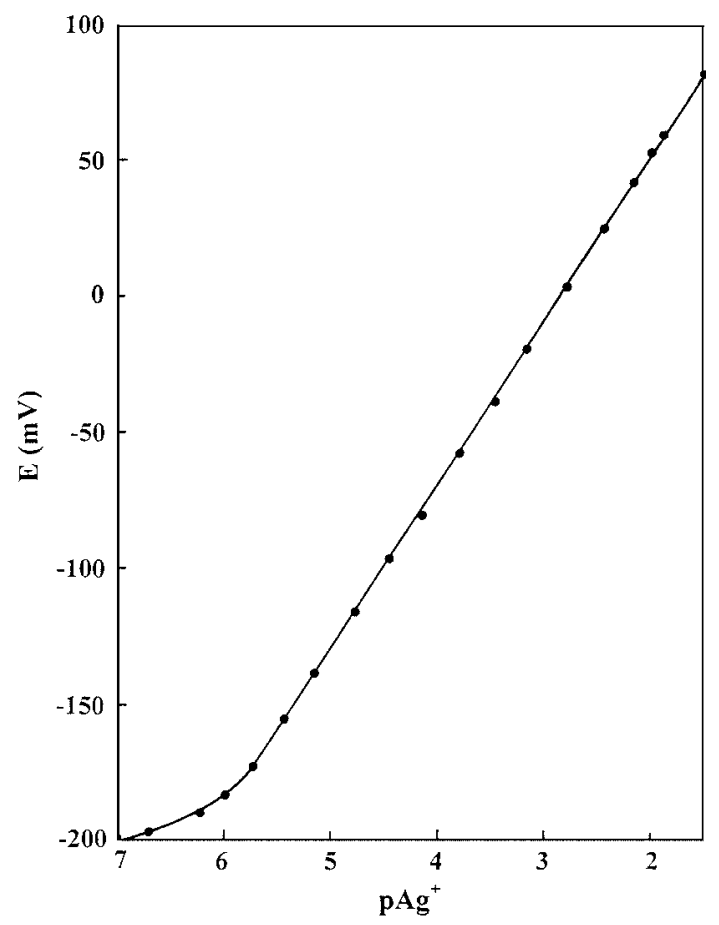

Figure 3. Calibration graph for the proposed $\mathrm{Ag}^{+}$ion-selective electrode.

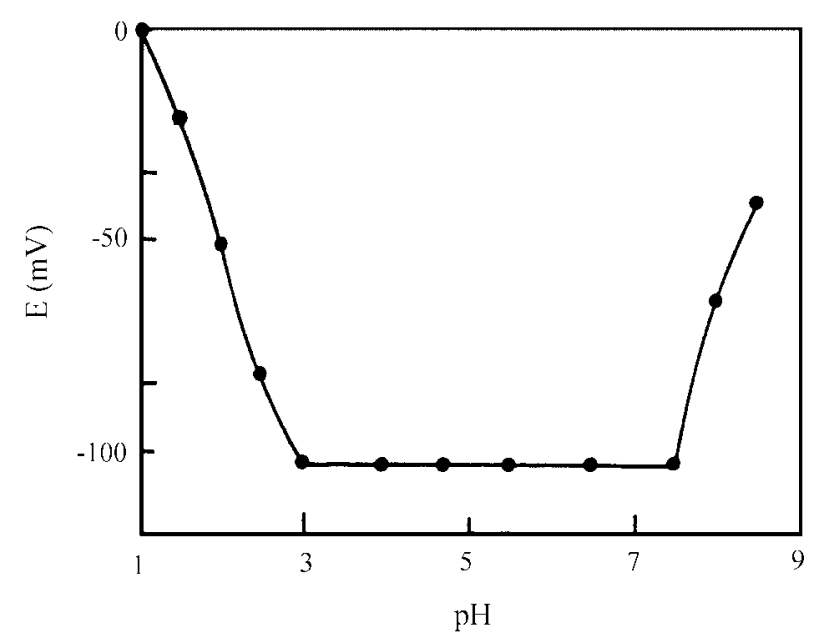

Figure 4. Effect of $\mathrm{pH}$ of test solution on the potential response of the $\mathrm{Ag}^{+}$ion-selective electrode.

change in response time, slope, or detection limit.

The PVC-membrane electrode prepared and operated under optimal experimental conditions shows a linear response to the activity of $\mathrm{Ag}^{+}$ion in the range of $1.7 \times 10^{-6}$ to $1.0 \times 10^{-1}$ $\mathrm{M}$ (Fig. 3). The slopes of the calibration plots were $60.2 \pm$ $0.7 \mathrm{mV}$ per decade of silver activity clange at $25^{\circ} \mathrm{C}$. The limit of detection was $7.0 \times 10^{-7} \mathrm{M}(0.076 \mathrm{ppm})$, as determined from the intersection of the two extrapolated segments of the calibration graph. The standard deviation of ten replicate potential measurements was $\pm 0.5 \mathrm{mV}$.

The influence of the $\mathrm{pH}$ of the test solution on the potential response of the $\mathrm{Ag}^{+}$-selective electrode was tested at a $5.0 \times 10^{-5} \mathrm{M}$ concentration over the $\mathrm{pH}$ range 1.0-8.5, (adjusted by either $\mathrm{HNO}_{3}$ or $\mathrm{KOH}$ ), and the results are shown in Figure 4. As seen. the potential remained constant from $\mathrm{pH}$ 3.0 to 7.5 . and the membrane electrode can be suitably used in this range of $\mathrm{pH}$. The observed drift at ligher $\mathrm{pH}$ values could be due to the interfering effect of the $\mathrm{K}^{+}$ion added (as $\mathrm{KOH}$ ). At low $\mathrm{pH}$, the potentials increased. indicating that the membrane electrode responds to hydrogen ions.

The selectivity behavior is obviously one of the most important characteristics of a membrane electrode, determining whether a reliable measurement in the target sample is possible. ${ }^{4.51}$ To assess the selectivity of the proposed silver ion-selective electrode over other cations, $\mathrm{M}^{\mathrm{n}}$, the methods of fixed interference (FIM) ${ }^{5}$ and mixed solution (MSM) ${ }^{53}$ were employed as described in our previous publications ${ }^{12.13 .28-31.41}$ The resulting $\mathrm{K}_{\mathrm{Ag}, \mathrm{M}}$ values for the proposed $\mathrm{Ag}^{+}$ion-selective electrode are summarized in Table $\mathrm{l}$. As seen, in all cases studied, the selectivity coefficients are in the order of $10^{-3}$ and smaller, enphasizing the highly selective behavior of the proposed membrane electrode for $\mathrm{Ag}^{-}$ion over many other monovalent and divalent cations of vastly different soft-hard character. ${ }^{54}$ Noteworthy is the fact that in most cases indicated in Table 1, the MSM results in more or less lower selectivity coefficient values than the FIM.

The practical utility of the proposed membrane electrode 
Table 1. Selectivity coefficients of various interfering ions

\begin{tabular}{|c|c|c|}
\hline $\mathrm{M}^{\mathrm{N}^{-}}$ & 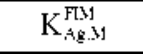 & 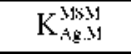 \\
\hline $\mathrm{Co}^{2+}$ & $7.9 \times 10^{-6}$ & $4.0 \times 10^{-5}$ \\
\hline $\mathrm{Ni}^{-}$ & $1.6 \times 10^{-4}$ & $6.3 \times 10^{-5}$ \\
\hline $\mathrm{Cul}^{2+}$ & $2.0 \times 10^{-4}$ & $6.3 \times 10^{-4}$ \\
\hline $\mathrm{Pb}^{2+}$ & $1.6 \times 10^{-4}$ & $2.3 \times 10^{-4}$ \\
\hline $\mathrm{Cd}^{2+}$ & $1.2 \times 10^{-4}$ & $1.0 \times 10^{-4}$ \\
\hline $\mathrm{Hg}^{2-}$ & $1.1 \times 10^{-\hat{2}}$ & $9.0 \times 10^{-3}$ \\
\hline $\mathrm{Mg}^{2+}$ & $1.9 \times 10^{-4}$ & $6.3 \times 10^{-5}$ \\
\hline $\mathrm{Ca}^{\hat{*}^{-}}$ & $1.8 \times 10^{-4}$ & $7.9 \times 10^{-5}$ \\
\hline $\mathrm{Sr}^{--}$ & $1.1 \times 10^{-4}$ & $5.0 \times 10^{-4}$ \\
\hline $\mathrm{Ba}^{\hat{2}}$ & $3.3 \times 10^{-4}$ & $4.0 \times 10^{-6}$ \\
\hline $\mathrm{Na}^{+}$ & $7.9 \times 10^{-3}$ & $1.2 \times 10^{-3}$ \\
\hline $\mathrm{K}^{+}$ & $5.0 \times 10^{-3}$ & $7.9 \times 10^{-4}$ \\
\hline $\mathrm{Tl}^{-}$ & $5.1 \times 10^{-5}$ & $2.0 \times 10^{-3}$ \\
\hline
\end{tabular}

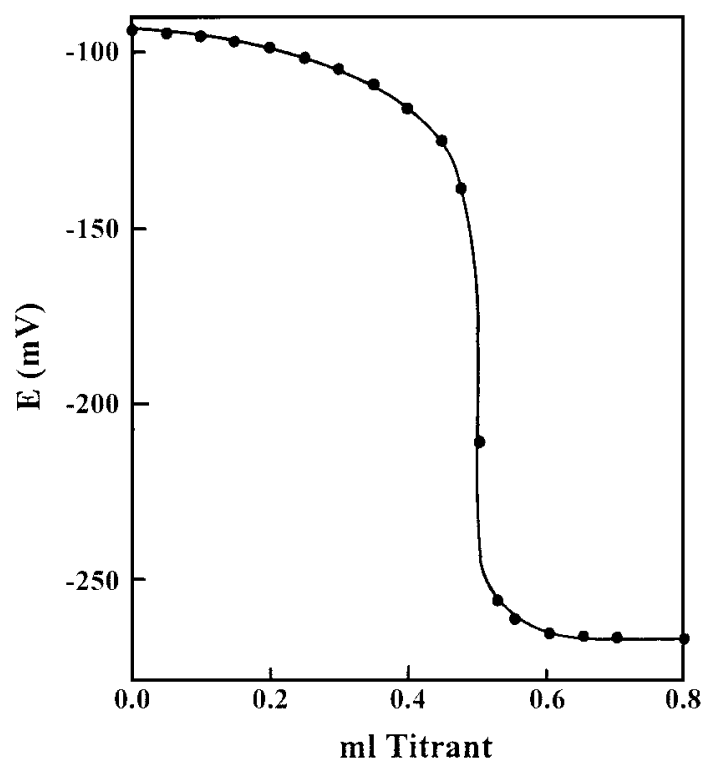

Figure 5. Potentiometric titration curve of $50.0 \mathrm{ml}$ of $4.9 \times 10^{-5} \mathrm{M}$ $\mathrm{AgNO}_{3}$ solution with $5.0 \times 10^{-2} \mathrm{M} \mathrm{KI}$, using the proposed sensor as an indicator electrode.

Table 2. Silver content of the final solutions of different samples ${ }^{a}$

\begin{tabular}{ccc}
\hline Sample & Ptoposed ISE & AAS \\
\hline Silver solder & $(6.3 \pm 0.2) \times 10^{-5} \mathrm{M}$ & $(6.2 \pm 0.1) \times 10^{-5} \mathrm{M}$ \\
Radiological film & $(5.1 \pm 0.3) \times 10^{-5} \mathrm{M}$ & $(5.0 \pm 0.1) \times 10^{-5} \mathrm{M}$ \\
$\begin{array}{c}\text { Photographic } \\
\text { developing solution }\end{array}$ & $(5.3 \pm 0.3) \times 10^{-5} \mathrm{M}$ & $(5.5 \pm 0.1) \times 10^{-5} \mathrm{M}$ \\
\hline
\end{tabular}

"The results of three replicate measurements.

was tested by its use as an indicator electrode for the titration of $50.0 \mathrm{~mL}$ of $4.9 \times 10^{-4} \mathrm{M}$ silver nitrate with a $5.0 \times 10^{-2} \mathrm{M}$ potassium iodide solution. and the resulting titration curve is shown in Figure 5. As seen, the amount of silver ions can be accurately determined with the electrode. The electrode was also successfully applied to the direct determination of silver content of a solder sample, a developed radiological film and a photographic developing solution, and the results, together with those obtained by AAS. are summarized in Table 2. As observed from Table 2, the results obtained by the proposed $\mathrm{Ag}^{-}$-selective electrode are in satisfactory agreement with those obtained by AAS.

\section{References}

1. Janata. J:- Jasowicz. M.; DeVaney. D. M. Anal. Chem. 1994. 66. $207 \mathrm{R}$.

2. De Marco. R. And. Chem. 1994. 66.3202.

3. Mayerhoff. M. E.: Opdyche. M. N. A d Ch: Chem 1986. 25. 1.

4. Moody, G. J.: Saad. B. B; Thomas. J. D. R. Sel Electrode Rev. 1988. 10,71 .

5. Kimura. K; Shono, T. In Cation Binding by Macrocycles: Inoue. Y.. Gokel. G. W.. Eds.: Marcel Dekker: New York. 1990.

6. Janata. T. Anol. Chem 1994. 64. 196R.

7. Bühlmant1. P.: Pretsch. E.: Bakiker. E. Chem. Rev 1998. 98.1593 and references therein.

8. Brzozka. Z. Anatyst 1988, 113, 1803.

9. Siswanta. D: Nagatsuka. K.: Yamada. H.: Kumakura. K.; Hisamoto. H.: Shichi. Y: Toshima. K.: Suzuki. K. Anal. Chent. 1996. 68. 1272 .

10. Yang. S.: Kumar. N.: Chi. H.: Hibbert. D. B.: Alexander. P. W. Electroanalusis 1997. 9. 549.

11. Gupta.V. K. Jain, S.: Khurana, U. Electroanalusis 1997. 9, 478.

12. Fakhari. A. R: Ganjali. M. R; Shamsipur. M. Anat. Chem 1997. 69.3693.

13. Fakhari. A. R.: Alaghemand. M.: Shamsipur. M. Anal Lett. 2000. 33. 2169.

14. An. H.: Bradshaw J. S.: Izatt. R. M. Chem. Rev 1992, 92. 543.

15. An. H.: Bradshaw. J. S.: Izatt. R. M.: Yan, Z. Chem. Rev 1994 94. 939.

16. Gibson. H. W.: Nagvekar. D. S. Cam. J. Chent 1997. 75. 1375.

17. Ibrahim. Y. A.: Elwahy. A. H. M. Sinthesis 1993. 503.

18. Sharghi. H.: Eshghi. H. Tetrohedhon 1995. 51.913.

19. Fukuda. N.; Ohtsu, T; Miwa. M:- Mashino, M.: Takoda. Y. Bull. Chem. Soc. Jpn. 1996. 69.1397.

20. Ganjali, M. R.: Eshghi. H.: Sharghi, H.: Shamsipur. M. d. Electronal. Chem. 1996. 405.177.

21. Kumar. S.: Handal. G.: Kaur. N.: Handal. M. S.: Singhl. M Tetwathedron Lett. 1997. 38. 131.

22. Adam, K. R.; Lindoy. L. F.; Lip. H. C.; Rea. J. H.: Skehon. B. W.: White. A. H. J. Chem. Soc, Dalon Trans. 1981, 74

23. Paredes. R. S.; Vaiera. N. S.: Lindoy, L. F. Atust. J. Chem. 1986. 39. 1071 .

24. Adam. K. R: Baldwin. D.: Duchworth. P. A.: Leong. A. T.: Lindoy. L. F.: McPartlin. M.: Tasker. P. D. J. Chent Soc. Chent. Commun. 1987. 1124.

25. Adam, K. R.: Leong. A. J:- Lindoy. L. F. J. Chem. Soc. Dalton Trans. 1988, 1733 .

26. Attiyat. A. S.: Ibrahim. Y. A.: Kadry. A. M.: Xie. R. Y.: Christiant. G. D. Fresenius Z. Anal Chem. 1987. 12.239.

27. Malinowska. E.: Turczak. J.: Stankiewicz. T. Electroma- hois 1993. 5,489 .

28. Shamsipur, M.; Rouhani. S.: Sharghi, H.; Ganjali, M. R.: Eshghi. H. Anal. Chem. 1999. 71. 4938.

29. Shamsipur. M.: Rouhani. S.: Ganjali. M. R.: Sharghi. H.: Eshghi. H. Sens. Actuators $B$ 1999.59.30.

30. Shamsipur. M.: Rouhani. S.: Ganjali. M. R.: Eshghi. H.: Sharghi. H. Aicrochem. J. $1999,63.2012$.

31. Javanbakht. M.: Ganjali. M. R.; Eshghi, $H_{\text {; }}$ Sharghi. $H$. : Shamsipur. M. Electroanalysis 1999, 11.81.

32. Kamata. S.: Bhale. A.: Fukunaga. Y: Murata. H. dinal Chent 1978. 60.2464.

33. Renter. H. In LIntams Envclopadie der Technischen-Chentie. $4^{\text {th }}$ ed.: Verlag Chemie: Weinheim. 1982: Vol. 21.

34. Soager. R. Matallic Raw Materials Dictionary: Bank Tobel: Zürick. 
1984.

35. Shamsipur. M.: Mashhadizadeh. M. H. Fesenits J Anal. Chem. 2000. 367.246

36. Siswanta. D: Nagatsuka. K.: Yamada. H: Kumakura. K.: Hisamoto, H.: Shichi, Y.: Toshima. K.: Suzuki, K. Anal. Chem. 1996, 68,4166 .

37. Chung, S.: Kim, W.: Park, S. B.: Kim, D. Y: Lee. S.S. Talanta 1997. H. 1291

38. Lee. S. S.: Aht1. M.-K.: Park. S. B. Anthlyt 1998. I23. 383.

39. Mashhadizadeh. M. H.: Shamsipur. M. Anat. Chim. Acta 1999. 381,111

40. Liu, D: Liu, J: Tian. D: Hong. W. Zhou, X: Yu, J. C. Anal. Chim. Acta 2000, $416,139$.

41. Anker. P: Wieland. E.: Ammann. D.: Dohner. R. E.: Asper. R: Simen. W. Alnat Chem. 1981. 53. 1970.

42. Armstrong. R. D.: Todd. M. J. Electroanal Chem. 1988. 257. 161.

43. Verpoorte. E. M. I.: Chan, A. D. C.: Harrison. D. J. Electroanal.
1993. 5,845 .

44. Bakker. E.: Bühlamann1. P.: Pretsch. E. Chent. Rev 1997. 97. 3033.

45. Schaller. U.: Bakker. E.: Spichiger. U. E.: Pretsch. E. Anal Chent 1994.66 .391

46. Ammann, D; Pretsch, E.: Simon, W: Lindner, E.: Bezegh, A: Poungor. E. Anal Chim Acta 1985. 171. 119.

47. Eugster, E; Gehring. P. M.; Morf, W. E; Spichiger. U.; Simon, W. Anal Chen 1991.63.2285.

48. Rostazin. T. : Bakker. E.: Suzuki. K.: Simon. W. Anal Chen. 1994. 66.391.

49. Ammann. D: Morf, W. E.: Anker, P: Meier. P. C.: Pretsch. E.; Simon. W. Ion-Sel Electrode Rev 1983. $5,3$.

50. Sun, B; Fitch, P. G. Electroanalysis 1997, 9. 494.

51. Bakker. E. Electroanalvsis 1997. 9.7.

52. Poungor. E.: Toth. K. Anal. Chim. Acta 1969. 47. 29

53. Srinivasan. K.: Rechnitz. G. A. Anal. Chent 1969. H. 1203.

54. Hancosk. R. D.: Martell. A. E. J. Chem. Educ. 1996, 73. 654 